\title{
The green economy transition: the challenges of technological change for sustainability
}

\author{
Patrik Söderholm(D)
}

\begin{abstract}
The Green Economy is an alternative vision for growth and development; one that can generate economic development and improvements in people's lives in ways consistent with advancing also environmental and social well-being. One significant component of a green economy strategy is to promote the development and adoption of sustainable technologies. The overall objective of this article is to discuss a number of challenges encountered when pursuing sustainable technological change, and that need to be properly understood by policy makers and professionals at different levels in society. We also identify some avenues for future research. The discussions center on five challenges: (a) dealing with diffuse - and ever more global - environmental risks; (b) achieving radical and not just incremental sustainable technological change; (c) green capitalism and the uncertain business-as-usual scenario; (d) the role of the state and designing appropriate policy mixes; and (e) dealing with distributional concerns and impacts. The article argues that sustainable technological change will require a re-assessment of the roles of the private industry and the state, respectively, and that future research should increasingly address the challenges of identifying and implementing novel policy instrument combinations in various institutional contexts.
\end{abstract}

Keywords: Green economy, Technological development, Radical innovation, green capitalism, Environmental policy, Policy mixes, Distributional effects

\section{The green economy transition and sustainable technological change}

Over the last decade, a frequent claim has been that the traditional economic models need to be reformed in order to address climate change, biodiversity losses, water scarcity, etc., while at the same time addressing key social and economic challenges. The global financial crisis in $2008-$ 2009 spurred this debate [4], and these concerns have been translated into the vision of a 'green economy' (e.g., [31, 33, 48, 54, 55]). Furthermore, in 2015, countries world-wide adopted the so-called 2030 Agenda for Sustainable Development and its 17 Sustainable Development Goals. These goals recognize that ending world poverty must go hand-in-hand with strategies that build economic growth but also address a range of various social needs

Correspondence: patrik.soderholm@ltu.se

Economics Unit, Luleå University of Technology, Luleå, Sweden including education, health, social protection, and job creation, while at the same time tackling environmental pollution and climate change. The sustainable development goals thus also establish a real link between the ecological system and the economic system. They also reinforce the need for a transition to a green economy, i.e., a fundamental transformation towards more sustainable modes of production and consumption.

In this article, we focus on a particularly important component of such a transition, namely the development of sustainable technological change, i.e., production and consumption patterns implying profoundly less negative impacts on the natural environment, including the global climate. Specifically, the article addresses a number of key challenges in supporting - and overcoming barriers to - sustainable technological change. These challenges are presented with the ambition to communicate important lessons from

(c) The Author(s). 2020 Open Access This article is licensed under a Creative Commons Attribution 4.0 International License, which permits use, sharing, adaptation, distribution and reproduction in any medium or format, as long as you give appropriate credit to the original author(s) and the source, provide a link to the Creative Commons licence, and indicate if changes were made. The images or other third party material in this article are included in the article's Creative Commons licence, unless indicated otherwise in a credit line to the material. If material is not included in the article's Creative Commons licence and your intended use is not permitted by statutory regulation or exceeds the permitted use, you will need to obtain permission directly from the copyright holder. To view a copy of this licence, visit http://creativecommons.org/licenses/by/4.0/. 
academic research to policy makers and professionals as well as the general public.

Addressing climate and environmental challenges, clearly requires natural scientific knowledge as well as engineering expertise concerning the various technical solutions that can be adopted to mitigate the negative impacts (e.g., carbon-free energy technologies). However, pursuing sustainable technological change is also a societal, organizational, political, and economic endeavor that involves several non-technical challenges. For instance, the so-called transitions literature recognizes that many sectors, such as energy generation, water supply etc., can be conceptualized as socio-technical systems and/or innovation systems [24, 40]. These systems consist of networks of actors (individuals, private firms, research institutes, government authorities, etc.), the knowledge that these actors possess as well as the relevant institutions (legal rules, codes of conduct, etc.). In other words, the development of, for instance, new carbon-free technologies may often require the establishment of new value chains hosting actors that have not necessarily interacted in the past; this necessitates a relatively long process that can alter society in several ways, e.g., through legal amendments, changed consumer behavior, distributional effects, infrastructure development and novel business models.

In other words, beyond technological progress, economic and societal adjustment is necessary to achieve sustainable technological change. In fact, history is full of examples that illustrate the need to address the organizational and institutional challenges associated with technological change and innovation. In hindsight, the societal impacts of electricity in terms of productivity gains were tremendous during the twentieth century. Still, while electrical energy was discovered in the late 1870s, in the year 1900, less than $5 \%$ of mechanical power in American factories was supplied by electric motors and it took yet another 20 years before their productivity soared [14]. An important reason for the slow diffusion of electric power was that in order to take full advantage of the new technology, existing factories had to change the entire systems of operation, i.e., the production process, the architecture, the logistics as well as the ways in which workers were recruited, trained and paid. ${ }^{1}$ A similar story emerges when considering the impact of computers on total productivity during the second half of the twentieth century. For long, many companies invested in computers for little or no reward. Also in this case, however, the new technology required systemic changes in order for companies to be able to take advantage of the computer. This meant, for instance, decentralizing, outsourcing, and streamlining supply chains as well as offering more choices to consumers [9].

\footnotetext{
${ }^{1}$ For instance, in the new system, workers had more autonomy and flexibility (e.g., [28]).
}

This key argument that the adoption of new technology has to be accompanied by systemic changes, applies both to the company as well as the societal level. Any novel solutions being developed must take into account the complexity of the interdependencies between different types of actors with various backgrounds, overall market dynamics, as well as the need for knowledge development and institutional reforms. In fact, the need for systemic changes may be particularly relevant in the case of green technologies, such as zero-carbon processes in the energy-intensive industries (see further below).

Against this background, the issue of how to promote sustainable technological change has received increasing attention in the policy arena and in academic research. The main objective of this article is therefore to discuss some of the most significant societal challenges in pursuing such change, and outline key insights for policy makers as well as important avenues for future research. In doing this, we draw on several strands of the academic literature. The article centers on the following five overall challenges:

- Dealing with diffuse - and ever more global environmental risks

- Achieving radical - and not just incremental sustainable technological change;

- The advent of green capitalism: the uncertain business-as-usual scenario

- The role of the state: designing appropriate policy mixes

- Dealing with distributional concerns and impacts

The first two challenges address the various types of structural tasks that are required to pursue sustainable technological change, and the barriers that have to be overcome when pursuing these tasks. The remaining points concern the role and the responsibility of different key actors in the transition process, not least private firms and government authorities. Each of these five challenges in turn involves more specific challenges, and these are identified and elaborated under each heading. We also provide hints about how to address and manage these challenges, but specific solutions will likely differ depending on the national or regional contexts. The paper concludes by briefly outlining some key avenues for future research, and with an emphasis on research that can assist a green socio-technical transition. ${ }^{2}$

\footnotetext{
${ }^{2}$ Clearly, given the focus on sustainable technological change, this article does not address all dimensions of the transition to a green economy. Heshmati [31] provides a recent review of the green economy concept, its theoretical foundations, political background and developmental strategies towards sustainable development. See also Megwai et al. [41] for an account of various green economy initiatives with a specific focus on developing countries, and Bartelmus [5] for a critical discussion of the link between the green economy and sustainable development.
} 


\section{Dealing with diffuse - and ever more global - environmental risks}

With the advent of modern environmental policy in the 1960s, stringent regulations were imposed on emissions into air and water. However, the focus was more or less exclusively on stationary pollution sources (i.e., industrial plants), which were relatively easy to monitor and regulate, e.g., through plant-specific emission standards. In addition, during this early era there was a strong emphasis on local environmental impacts, e.g., emissions into nearby river basins causing negative effects on other industries and/or on households in the same community.

Over the years, though, the environmental challenges have increasingly been about targeting various types of diffuse emissions. These stem from scattered sources such as road transport, shipping, aviation, and agriculture. Pollution from diffuse sources takes place over large areas and individually they may not be of concern, but in combination with other diffuse sources they can cause serious overall impacts. The growing importance of global environmental challenges such as climate change in combination with globalization and more international trade in consumer products, adds to this challenge. Managing these issues often requires international negotiations and burden-sharing, which in itself have proved difficult [12]. The difficulties in reaching a stringent-enough global climate agreement illustrate this difficulty.

Diffuse emissions are typically difficult to monitor and therefore also to regulate. For instance, environmental authorities may wish to penalize improper disposal of a waste product since this would help reduce various chemical risks, but such behavior is typically clandestine and difficult to detect. Plastic waste is an apt example; it stems from millions of consumer products, is carried around the world by the currents and winds, and builds up microplastics, particularly in the sea. Many dangerous substances, including chemicals such as solvents and phthalates, are embedded in consumer products, out of which many are imported. Monitoring the potential spread of these substances to humans and the natural environment remains difficult as well. Technological innovation that permits better tracing and tracking of materials should therefore be a priority (see also [21]).

In order to address these diffuse environmental impacts, society has to find alternative - yet more indirect - ways of monitoring and regulating them. This could translate into attempts to close material cycles and promote a circular economy, i.e., an economy in which the value of products, materials and resources are maintained as long as possible [19]. In practice, this implies an increased focus on reduction, recycling and re-use of virgin materials [30], material and energy efficiency, as well as sharing of resources (often with the help of various digital platforms such as Uber and Airbnb). In other words, rather than regulating emissions as close to damage done as possible, the authorities may instead support specific activities (e.g., material recycling) and/ or technologies (e.g., low-carbon production processes) that can be assumed to correlate with reduced environmental load.

Addressing diffuse emissions in such indirect ways, though, is not straightforward. In several countries, national waste management strategies adhere to the socalled waste hierarchy (see also the EU Waste Framework Directive). This sets priorities for which types of action should be taken, and postulates that waste prevention should be given the highest priority followed by re-use of waste, material recycling, recovery of waste and landfill (in that order). Even though research has shown that this hierarchy is a reasonable rule of thumb from an environmental point of view [42], it is only a rule of thumb! Deviations from the hierarchy can be motivated in several cases and must therefore be considered (e.g., [58]). ${ }^{3}$

One important way of encouraging recycling and reuse of products is to support product designs that factor in the reparability and reusability of products. Improved recyclability can also benefit from a modular product structure (e.g., [20]). However, this also comes with challenges. Often companies manufacture products in such ways that increase the costs of recycling for downstream processors, but for institutional reasons, there may be no means by which the waste recovery facility can provide the manufacturer with any incentives to change the product design $[11,46]$. One example is the use of multi-layer plastics for food packaging, which could often be incompatible with mechanical recycling.

While the promotion of material and energy efficiency measures also can be used to address the problem of diffuse environmental impacts, it may be a mixed blessing. Such measures imply that the economy can produce the same amount of goods and services but with less material and energy inputs, but they also lead to a so-called rebound effect [27]. Along with productivity improvements, resources are freed and can be used to increase the production and consumption of other goods. In other words, the efficiency gains may at least partially be cancelled out by increased consumption elsewhere in the economy. For instance, if consumers choose to buy fuel-efficient cars, they are able to travel more or spend the money saved by lower fuel use on other products, which in turn will exploit resources and lead to emissions.

${ }^{3}$ For instance, it is typically less negative for the environment to landfill a substantial share of mining waste such as hard rock compared to recycling. Hard rock typically causes little environmental damage, except aesthetically, unless such waste interacts with surface or ground water [17]. 
Finally, an increased focus on circular economy solutions will imply that the different sectors of the economy need to become more interdependent. This interdependency is indeed what makes the sought-after efficiency gains possible in the first place. This in turn requires new forms of collaborative models among companies, including novel business models. In some cases, though, this may be difficult to achieve. One example is the use of excess heat from various process industries; it can be employed for supplying energy to residential heating or greenhouses. Such bilateral energy cooperation is already quite common (e.g., in Sweden), but pushing this even further may be hard and/or too costly. Investments in such cooperation are relation-specific [60], i.e., their returns will depend on the continuation of the relationships. The involved companies may be too heterogeneous in terms of goals, business practices, planning horizons etc., therefore making long-term commitment difficult. Moreover, the excess heat is in an economic sense a byproduct, implying that its supply will be constrained by the production of the main product. Of course, this is valid for many other types of waste products as well, e.g., manure digested to generate biogas, secondary aluminum from scrapped cars.

In brief, the growing importance of addressing diffuse emissions into the natural environment implies that environmental protection has to build on indirect pollution abatement strategies. Pursuing each of these strategies (e.g., promoting recycling and material efficiency), though, imply challenges; they may face important barriers (e.g., for product design, and byproduct use) and could have negative side-effects (e.g., rebound effects). Moreover, a focus on recycling and resource efficiency must not distract from the need to improve the tracing and tracking of hazardous substances and materials as well as provide stronger incentives for product design. Both technological and organizational innovations are needed.

\section{Achieving radical - and not just incremental - sustainable technological change}

Incremental innovations, e.g., increased material and energy efficiency in existing production processes, are key elements for the transition to a green economy. However, more profound - and even radical - technological innovation is also needed. For instance, replacing fossil fuels in the transport sector as well as in iron and steel production requires fundamental technological shifts and not just incremental efficiency improvements (e.g., [1]). There are, however, a number of factors that will make radical innovation inherently difficult. Below, we highlight three important obstacles.

First, one obstacle is the risk facing firms that invest in technological development (e.g., basic R\&D, pilot tests etc.) in combination with the limited ability of the capital market to handle the issue of long-term risktaking. These markets may fail to provide risk management instruments for immature technology due to a lack of historical data to assess risks. There are also concerns that the deregulation of the global financial markets has implied that private financial investors take a more short-term view [44]. In fact, research also suggests that due to agency problems within private firms, their decision-making may be biased towards short-term payoffs, thus resulting in myopic behavior also in the presence of fully efficient capital markets [53].

Second, private investors may often have weak incentives to pursue investments in long-term technological development. The economics literature has noted the risks for the under-provision of public goods such as the knowledge generated from R\&D efforts and learning-bydoing (e.g., [38]). Thus, private companies will be able to appropriate only a fraction of the total rate-of-return on such investment, this since large benefits will also accrue to other companies (e.g., through reverse engineering). Due to the presence of such knowledge spillovers, investments in long-term technological development will become inefficient and too modest.

Third, new green technologies often face unfair competition with incumbent technologies. The incumbents, which may be close substitutes to their greener competitors, will be at a relative competitive advantage since they have been allowed to expand during periods of less stringent environmental policies as well as more or less tailor-made institutions and infrastructures. This creates path-dependencies, i.e. where the economy tends to be locked-in to certain technological pathways [2]. In general, companies typically employ accumulated technology-specific knowledge when developing new products and processes, and technology choices tend to be particularly self-reinforcing if the investments are characterized by high upfront costs and increasing returns from adoption (such as scale, learning and network economies). Existing institutions, e.g., laws, codes of conduct, etc., could also contribute to path dependence since these often favor the incumbent (e.g., fossil-fuel based) technologies [57].

The above three factors tend to inhibit all sorts of long-run technological development in the private sector, but there is reason to believe that they could be particularly troublesome in the case of green technologies. First, empirical research suggests that green technologies (e.g., in energy and transport) generate large knowledge spillovers than the dirtier technologies they replace $[15,49]$. Moreover, while the protection of property rights represents one way to limit such spillovers, the patenting system is subject to limitations. For instance, Neuhoff [43] remarks that many sustainable technologies: 
"consist of a large set of components and require the expertise of several firms to improve the system. A consortium will face difficulties in sharing the costs of 'learning investment', as it is difficult to negotiate and fix the allocation of future profits," (p. 98).

These are generally not favorable conditions for effective patenting. Process innovations, e.g., in industry, are particularly important for sustainable technology development, but firms are often more likely to employ patents to protect new products rather than new processes [39].

Furthermore, one of the key socio-technical systems in the green economy transition, the energy system, is still today dominated by incumbent technologies such as nuclear energy and fossil-fueled power, and exhibits several characteristics that will lead to path dependent behavior. Investments are often large-scale and exhibit increasing returns. Path dependencies are also aggravated by the fact that the outputs from different energy sources and regardless of environmental performance - are more or less perfect substitutes. In other words, the emerging and carbon-free technologies can only compete on price with the incumbents, and they therefore offer little scope for product differentiation. In addition, the energy sectors are typically highly regulated, thus implying that existing technological patterns are embedded in and enforced by a complex set of institutions as well as infrastructure.

In brief, technological change for sustainability requires more radical technological shifts, and such shifts are characterized by long and risky development periods during which new systemic structures - i.e., actor networks, value chains, knowledge, and institutions - need to be put in place and aligned with the emerging technologies. Overall, the private sector cannot alone be expected to generate these structures, and for this reason, some kind of policy support is needed. Nevertheless, in order for any policy instrument or policy mix to be efficient, it has to build on a proper understanding of the underlying obstacles for long-run technological development. As different technologies tend to face context-specific learning processes, patenting prospects, risk profiles etc., technology-specific support may be needed (see also below).

\footnotetext{
${ }^{4}$ In fact, patents protecting intellectual property rights could even slow down the diffusion of green technologies offering deep emission reductions by creating a bias towards development of close-tocommercial technologies. For instance, Budish et al. [10] shows that while patents award innovating companies a certain period of market exclusivity, the effective time period may be much shorter since some companies choose to file patents at the time of discovery rather than at first sale. One consequence of this is that the patent system may provide weak incentives for companies to engage in knowledge generation and learning about technologies that face a long time between invention and commercialization.
}

\section{The advent of green capitalism: the uncertain business-as-usual scenario}

At least since the advent of the modern environmental debate during the 1960s, economic and environmental goals have been perceived to be in conflict with each other. Business decisions, it has been argued, build on pursuing profit-maximization; attempts to address environmental concerns simultaneously will therefore imply lower profits and reduced productivity. However, along with increased concerns about the environmental footprints of the global economy and the growth of organic products and labels, material waste recycling, climate compensation schemes etc., sustainability issues have begun to move into the mainstream business activities. In fact, many large companies often no longer distinguish between environmental innovation and innovation in general; the environmental footprints of the business operations are almost always taken into consideration during the innovation process (e.g., [47]).

Some even puts this in Schumpeterian terms, and argues that sustainable technological change implies a "new wave of creative destruction with the potential to change fundamentally the competitive dynamics in many markets and industries," ([37], p. 315). The literature has recognized the potentially important roles that so-called sustainability entrepreneurs can play in bringing about a shift to a green economy; these types of entrepreneurs seek to combine traditional business practices with sustainable development initiatives (e.g., [25]). They could disrupt established business models, cultures and consumer preferences, as well as help reshape existing institutions. Just as conventional entrepreneurs, they are agents of change and offer lessons for policy makers. However, the research in this field has also been criticized for providing a too strong focus on individual success stories, while, for instance, the institutional and political factors that are deemed to also shape the priorities made by these individuals tend to be neglected (e.g., [13]).

Ultimately, it remains very difficult to anticipate how far voluntary, market-driven initiatives will take us along the long and winding road to the green economy. In addition to a range of incremental developments, such as increased energy and material efficiency following the adoption of increased digitalization, industrial firms and sustainability entrepreneurs are likely to help develop new and/or refined business models (e.g., to allow for increased sharing and recycling of resources) as well as adopt innovations commercially. In the future, businesses are also likely to devote greater attention to avoiding future environmental liabilities, such as the potential costs of contaminated land clean-up or flood risks following climate change. Far from surprising, large insurance companies were among the first to view climate change as a risk to their viability. One response was the 
development of new financial instruments such as 'weather derivatives' and 'catastrophe bonds' [35].

In other words, there is an increasing demand for businesses that work across two logics that in the past have been perceived as incompatible: the commercial and the environmental. There are however huge uncertainties about the scope and the depth of green capitalism in this respect. Moreover, the answer to the question of how far the market-driven sustainability transition will take us, will probably vary depending on business sector and on factors such as the availability of funding in these sectors. ${ }^{5}$

As indicated above, there are reasons to assume that in the absence of direct policy support, businesses will not be well-equipped to invest in long-term green technology development. Green product innovations may often be easier to develop and nurture since firms then may charge price premiums to consumers. In fact, many high-profile sustainability entrepreneurs in the world (e.g., Anita Roddick of The Body Shop) have been product innovators. In contrast, green process innovation is more difficult to pursue. It is hard to get consumers to pay premiums for such innovations. For instance, major efforts are needed to develop a carbon-free blast furnace process in modern iron and steel plants (e.g., [1]). And even if this is achieved, it remains unclear whether the consumers will be willing to pay a price premium on their car purchases purely based on the knowledge that the underlying production process is less carbon-intense than it used to be. Moreover, taking results from basic $R \& D$, which appear promising on the laboratory scale, through "the valley of death" into commercial application is a long and risky journey. Process innovations typically require gradual up-scaling and optimization of the production technologies (e.g., [29]). For small- and medium-sized firms in particular, this may be a major hurdle.

In brief, the above suggests that it is difficult to anticipate what a baseline scenario of the global economy i.e., a scenario involving no new policies - would look like from a sustainability perspective. Still, overall it is likely that green capitalism and sustainability entrepreneurship alone may have problems delivering the green economy transition in (at least) two respects. First, due to the presence of knowledge spillovers and the need for long-term risk-taking, the baseline scenario may involve too few radical technology shifts (e.g., in process industries). Second, the baseline scenario is very likely to involve plenty of digitalization and automation, in turn considerably increasing the potential for material and

${ }^{5}$ The UNFCCC [56] reports substantial increases in climate-related global finance flows, but these flows are still relatively small in the context of wider trends in global investment. They are even judged to be insufficient to meet the additional financing needs required for adaptation to the climate change that cannot be avoided. energy efficiency increases. Nevertheless, due to rebound effects, the efficiency gains resulting from new technologies alone may likely not be enough to address the sustainability challenge. This therefore also opens up the field for additional policy support, and - potentially - a rethinking of the role of the state in promoting sustainable technological change.

\section{The role of the state: designing appropriate policy mixes}

An important task for government policy is to set the appropriate "framework conditions" for the economy. This refers primarily to the legal framework, e.g., immaterial rights, licensing procedures, as well as contract law, which need to be predictable and transparent. Traditional environmental policy that regulates emissions either through taxes or performance standards will remain important, as will the removal of environmentally harmful subsidies (where such exist). The role of such policies is to make sure that the external costs of environmental pollution are internalized in firms' and households' decision-making (e.g., [7]). Still, in the light of the challenges discussed above - i.e., controlling diffuse emissions, the need for more fundamental sustainable technological change, as well as the private sector's inability to adequately tackle these two challenges - the role of the state must often go beyond providing such framework conditions. In fact, there are several arguments for implementing a broader mix of policy instruments in the green economy.

In the waste management field, policy mixes may be needed for several reasons. For instance, previous research shows that in cases where diffuse emissions cannot be directly controlled and monitored, a combined output tax and recycling subsidy (equivalent to a deposit-refund system) can be an efficient second-best policy instrument mix (e.g., [59]). This would reduce the amount of materials entering the waste stream, while the subsidy encourages substitution of recycled materials for virgin materials. ${ }^{6}$ An extended waste management policy mix could also be motivated by the limited incentives for manufacturers of products to consider product design and recyclability, which would decrease the costs of downstream recycling by other firms. This is, though, an issue that often cannot be addressed by traditional policies such as taxes and standards; it should benefit from technological and organizational innovation. Finally, the establishment of efficient markets for recycled materials can also be hampered by different types of information-related obstacles, including byers' inability to assess the quality of mixed waste streams. In such a case, information-based policies based

${ }^{6}$ If the tax is assessed per pound of intermediate material produced, it will also give producers the incentive to supply lighter-weight products. 
on, for instance, screening requirements at the waste sites could be implemented (e.g., [46]).

At a general level, fostering green technological development, not least radical innovation, must also build on a mix of policies. The literature has proposed an innovation policy mix based on three broad categories of instruments (see also $[36,51,52]$ ):

1. Technology-push instruments that support the provision of basic and applied knowledge inputs, e.g., through R\&D grants, patent protection, tax breaks etc.

2. Demand-pull instruments that encourage the formation of new markets, e.g., through deployment policies such as public procurement, feed-in tariffs, quotas, etc.

3. Systemic instruments that support various functions operating at the innovation system level, such as providing infrastructure, facilitating alignment among stakeholders, and stimulating the development of goals and various organizational solutions.

A key role for a green innovation policy is to support the development of generic technologies that entrepreneurial firms can build upon [50]. Public R\&D support and co-funding of pilot and demonstration plants help create variation and permit new inventions to be verified, optimized and up-scaled. As noted above, there is empirical support for public R\&D funding of green technology development, as underinvestment due to knowledge spillovers might be particularly high for these technologies.

As the technology matures, though, it must be tested in a (niche) market with real customers, and the state will often have to create the conditions for private firms to raise long-term funding in areas where established financial organizations are not yet willing to provide sufficient funds. For instance, in the renewable energy field, this has been achieved by introducing feed-in tariffs or quota schemes for, for instance, wind power and solar PV technology (e.g., [16]). Finally, well-designed systemic instruments will have positive impacts on the functioning of the other instruments in the policy mix; while technology-push and demand-pull instruments are the engines of the innovation policy mix, the systemic instruments will help that engine run faster and more efficiently.

The implementation of the above policy mixes will be associated with several challenges, such as gaining political acceptability, identifying the specific designs of the policy instruments, and determining how these instruments can be evaluated. All these issues deserve attention in future research. Still, here we highlight in particular the need for policies that are technology- specific; i.e., in contrast to, for instance, pollution taxes or generic R\&D subsidies they promote selected technological fields and/or sectors. Based on the above discussions one can point out two motives for relying on technology-specific instruments in promoting sustainable technological change: (a) the regulations of diffuse emissions can often not target diffuse emissions directly - at least not without incurring excessively high monitoring costs; and (b) the need to promote more radical environmental innovations.

The innovation systems surrounding green energy technology tend to be technology-specific. Different technologies are exposed to unique and multi-dimensional growth processes, e.g., in terms of bottlenecks, learning processes, and the dynamics of the capital goods industries [34]. The nature of the knowledge spillovers and the long-term risks will also differ as will the likelihood that green technologies suffer from technological lock-in associated with incumbent technology (e.g., [38]). For instance, the technological development process for wind power has been driven by turbine manufacturers and strong home markets, while equipment suppliers and manufacturers that own their own equipment have dominated solar PV development [32].

Clearly, technology-specific policies are difficult to design and implement; regulators typically face significant information constraints and their decisions may also be influenced by politico-economic considerations such as bureaucratic motives, and lobby group interests. Moreover, the prospects for efficient green technology-specific policies may likely also differ across jurisdictions; some countries will be more likely to be able to implement policies that can live up to key governing principles such as accountability, discipline and building on arms-length interactions with the private sector. As noted by Rodrik [50], "government agencies need to be embedded in, but not in bed with, business," (p. 485).

The above begs the question whether the governance processes at the national and the supra-national levels (e.g., the EU) are in place to live up to a more proactive and transformative role for the state. Newell and Paterson [45] argue that such a state needs to balance two principles that have for long been seen as opposed to one another. These are, one the one hand, the empowerment of the state to actively determine priorities and, on the other, "providing citizens with more extensive opportunities to have a voice, to get more involved in decision-making processes, and to take on a more active role in politics," (p. 209). The latter issue is further addressed also in the next section.

In brief, the climate and environmental challenges facing society today require a mix of policy instruments, not least because the barriers facing new sustainable technology are multi-faceted and often heterogeneous 
across technologies. Supporting green innovation should build on the use of technology-specific policies as complements to traditional environmental policies. This in itself poses a challenge to policy-making, and requires in-depth understanding of how various policy instruments interact as well as increased knowledge about the institutional contexts in which these instruments are implemented.

\section{Dealing with distributional concerns and impacts}

The transition to a green economy, including technological change, affects the whole of society. It is therefore necessary to not only optimize the performance of the new technologies and identify efficient policies; the most significant distributional impacts of technological change must also be understood and addressed. All societal changes involve winners and losers, and unless this is recognized and dealt with, the sought-after green transition may lack in legitimacy across various key groups in society. Bek et al. [6] provide an example of a green economy initiative in South Africa - the so-called Working for Water (WfW) program - that has failed to fully recognize the social aspects of the program goals.

This challenge concerns different dimensions of distributional impacts. One such dimension is how households with different income levels are affected. Economics research has shown that environmental policies in developed countries, not least taxes on pollution and energy use, tend to have regressive effects [22], thus implying that the lowest-income households are generally most negatively affected in relative terms. Such outcomes may in fact prevail also in the presence of policies that build on direct support to certain technological pathways. For instance, high-income households are likely to benefit the most from subsidies to solar cells and electric cars, this since these households are more likely to own their own house as well as to be more frequent car buyers. Of course, technological change (e.g., digitalization, automation etc.), including that taking place in green technology, may also have profound distributional impacts in more indirect ways, not the least through its impacts on the labor market (e.g., wages. Work conditions) (e.g., [3]).

The regional dimension of sustainable development is also important (e.g., [26]). One challenge in this case is that people increasingly expect that any green investments taking place in their own community (e.g., in wind power) should promote regional growth, employment and various social goals. The increased emphasis on the distributional effects at the regional level can also be attributed to the growing assertion of the rights of people (e.g., indigenous rights), and increased demands for direct participation in the relevant decision-making processes. However, new green technology may fail to generate substantial positive income and employment impacts at the local and regional level. For instance, one factor altering the renewable energy sector's relationship with the economy has been technological change. A combination of scale economies and increased capital intensity has profoundly increased the investment capital requirements of facilities such as wind mill parks and biofuel production facilities. The inputs into modern green energy projects increasingly also have to satisfy high standards in terms of know-how, and these can therefore not always be supplied by local firms (e.g., [18]). Indeed, with the implementation of digital technology, the monitoring of, say, entire wind farms can today be done by skilled labor residing in other parts of the country (or even abroad).

Ignoring the distributional effects of sustainable technological change creates social tensions, thereby increasing the business risks for companies and sustainability entrepreneurs. Such risks may come in many forms. For instance, reliability in supply has become increasingly important, and customers will generally not be very forgiving in the presence of disruptions following the emergence of tense community relations. Furthermore, customers, fund managers, banks and prospective employees do not only care about the industry's output, but increasingly also about how the products have been produced.

In fact, while the economies of the world are becoming more integrated, political trends are pointing towards a stronger focus on the nation state and even on regional independence. If anything, this will further complicate the green economy transition. Specifically, it will need to recognize the difficult trade-offs between efficiency, which typically do require international coordination (e.g., in terms of policy design, and R\&D cooperation), and a fair distribution of benefits and costs, which instead tends to demand a stronger regional and local perspective.

In brief, the various distributional effects of sustainable technological change deserve increased attention in both scholarly research and the policy domain in order to ensure that this change emerges in ways that can help reduce poverty and ensure equity. These effects may call for an even broader palette of policies (e.g., benefitsharing instruments, such as regional or local natural resource funds, compensation schemes, or earmarked tax revenues), but they also call for difficult compromises between efficiency and fairness.

\section{Conclusions and avenues for future research}

The scope and the nature the societal challenges that arise as a consequence of the climate and environmental hazards are complex and multi-faceted, and in this article we have focused on five important challenges to sustainable technological change. These challenges are 
generic, and should be a concern for most countries and regions, even though the specific solutions may differ depending on context. In this final section, we conclude by briefly discussing a number of implications and avenues for future research endeavors. ${ }^{7}$ These knowledge gaps may provide important insights for both the research community as well as for policy makers and officials.

It should be clear that understanding the nature of - as well as managing - socio-technical transitions represents a multi-disciplinary research undertaking. Collaborations between natural scientists and engineers on the one hand and social scientists on the other are of course needed to translate environmental and technical challenges into societal challenges and action. In such collaborative efforts, however, it needs to be recognized that technological change is not a linear process; it entails phases such as concept development, pilot and demonstration projects, market formation and diffusion of technology, but also with important iterations (i.e., feedback loops) among all of these phases. It should be considered how bridges between different technical and social science disciplines can be built, this in order to gain a more in-depth understanding of how technology-specific engineering inventions can be commercialized in various institutional contexts. Transition studies, innovation and environmental economics, as well the innovation system and the innovation management literatures, among others, could help provide such bridges. Other types of systems studies, e.g., energy system optimization modeling, will also be important.

In addition to the above, there should also be an expanded role for cross-fertilization among different social sciences, e.g., between the economics, management and political science fields and between the research on sustainability entrepreneurs and transition studies (see also [26]). This could help improve the micro-foundations of, for instance, innovation system studies, i.e., better understanding of companies' incentives, drivers etc., but also stress the need for considering socio-technical systems in the management research. For instance, the focus on individual heroes that pervades much of the entrepreneurship literature may lead to a neglect of the multiple factors at work and the role of framework conditions such as institutions (e.g., legal rules, norms) and infrastructure at the national and local scales. Better integration of various conceptual perspectives on green business and innovation could generate less uncertain business-as-usual scenarios.

\footnotetext{
${ }^{7}$ See also Future Earth [23] for a comprehensive list of priorities for a global research sustainability agenda.
}

The discussions in this article also suggest that green innovation in the public sector should be devoted more attention in future research. This could, of course, focus on various institutional and organizational innovations in the form of new and/or revised policy instrument design. The challenges involved in designing and implementing technology-specific sustainability policies, typically referred to as green industrial policies [50], tend to require such innovation (e.g., to increase transparency, and avoid regulatory capture). These policies are essentially processes of discovery, both by the state and the industry, rather than a list of specific policy instruments. This implies learning continuously about where the constraints and opportunities lie, and then responding to these.

The risk associated with regulatory capture is one issue that deserves increased attention in future research, including how to overcome such risks. Comparisons of green industrial policies across countries and technological fields - as well as historical comparative studies - could prove useful (e.g., [8]). How different policies interact as well as what the appropriate level of decision-making power is, are also important questions to be addressed. Of course, given the context-specificity of these types of policies, such research must also address the issue of how transferable innovation and sustainable practices are from one sociotechnical and political context to another.

Moreover, the growing importance of diffuse emissions also requires green innovation in the public sector. Specifically, implementing environmental regulations that are close to damages demand specific monitoring technologies that can measure pollution levels. The development of new technologies - which, for instance, facilitates cheap monitoring of emissions - ought to be promoted, but it is quite unclear who has the incentive to promote and undertake such R\&D activities. Similar concerns can be raised about the innovations that permit consumers to better assess the environmental footprints of different products and services (e.g., [21]). Private firms cannot be expected to pursue these types of green innovations intensively. Nevertheless, governments often spend substantial amounts on funding $R \& D$ on pollution abatement technology, but less frequently we view government programs funding research on technologies that can facilitate policy enforcement and environmental monitoring.

Finally, the green economy transition should also benefit from research that involves various impact evaluations, including methodological innovation in evaluation studies. This concerns evaluations of the impacts of important baseline trends, e.g., digitalization and automation, globalization versus nationalization, etc., on environmental and distributional outcomes but also on the prospects for green innovation collaborations and various circular economy-inspired business models. Such 
evaluations could be particularly relevant for understanding possible future pathways for the greening - and de-carbonization - of key process industries. Clearly, there is also need for improved evaluations of policy instruments and combinations of policies. With an increased emphasis on the role of technology-specific policies, such evaluations are far from straightforward. They must consider the different policies' roles in the innovation systems, and address important interaction effects; any evaluation must also acknowledge the policy learning taking place over time.

\section{Acknowledgements}

Financial support from Nordforsk (the NOWAGG project) is gratefully acknowledged, as are valuable comments on earlier versions of the manuscript from Åsa Ericson, Johan Frishammar, Jamil Khan, Annica Kronsell, one anonymous reviewer and the Editor. Any remaining errors, however, reside solely with the author

\section{Authors' contributions}

Single-authored article. The author(s) read and approved the final manuscript.

\section{Funding}

Financial support from Nordforsk and the NOWAGG project on Nordic green growth strategies is gratefully acknowledged. Open access funding provided by Lulea University of Technology.

\section{Availability of data and materials}

Not applicable.

\section{Ethics approval and consent to participate}

Not applicable.

\section{Consent for publication}

Not applicable.

\section{Competing interests}

The authors declare that they have no competing interests.

Received: 24 July 2019 Accepted: 5 January 2020

Published online: 22 June 2020

\section{References}

1. Åhman M, Nilsson LJ, Johansson B. Global climate policy and deep decarbonization of energy-intensive industries. Clim Pol. 2017;17(5):634-49.

2. Arthur WB. Competing technologies, increasing returns, and lock-in by historical small events. Econ J. 1989;99:116-31.

3. Avent R. The wealth of humans: work, power, and status in the twenty-firs century. London: St. Martin's Press; 2016.

4. Barbier E. How is the global green new deal going? Nature. 2010;464:832-3.

5. Bartelmus $P$. The future we want: green growth or sustainable development? Environ Dev. 2013;7:165-70.

6. Bek D, Nel E, Binns T. Jobs, water or conservation? Deconstructing the green economy in South Africa's working for water programme. Environ Dev. 2017;24:136-45.

7. Bennear LS, Stavins RN. Second-best theory and the use of multiple policy instruments. Environ Resour Econ. 2007;37:111-29.

8. Bergquist AK, Söderholm K, Kinneryd H, Lindmark M, Söderholm P. Command-and-control revisited: environmental compliance and technological change in Swedish industry 1970-1990. Ecol Econ. 2013; 85:6-19.

9. Brynjolfsson E, Hitt LM. Computation: information technology, organizational trans-formation and business performance. J Econ Perspect. 2000;14:23-48

10. Budish $\mathrm{E}$, Roin $\mathrm{BN}$, Williams $\mathrm{H}$. Do firms underinvest in long-term research? Evidence from cancer clinical trials. Am Econ Rev. 2015;105(7):2044-85
11. Calcott P, Walls M. Waste, recycling, and 'design for environment': roles for markets and policy instruments. Resour Energy Econ. 2005;27(4):287-305.

12. Ciscar J-C, Saveyn B, Soria A, Szabo L, Van Regemorter D, Van lerland T. A comparability analysis of global burden sharing GHG reduction scenarios. Energy Policy. 2013;55:73-81.

13. Cohen B. Sustainable valley entrepreneurial ecosystems. Bus Strateg Environ. 2006;15(1):1-14

14. David P. The computer and the dynamo: an historical perspective. Am Econ Rev. 1990;80:355-61.

15. Dechezleprêtre A, Glachant M, Mohnen M. Knowledge spillovers from clean and dirty technologies: a patent citation analysis. Working paper no. 135. London: Grantham Research Institute on Climate Change and the Environment; 2017.

16. Del Rio P, Bleda M. Comparing the innovation effects of support schemes for renewable electricity technologies: a function of innovation approach. Energy Policy. 2012;50:272-82.

17. Eggert RG, editor. Mining and the environment: international perspectives on public policy. Washington, DC: Resources for the Future; 1994.

18. Ejdemo T, Söderholm P. Wind power, regional development and benefit-sharing: the case of northern Sweden. Renew Sust Energ Rev. 2015:47:476-85

19. European Commission. Closing the loop - an EU action plan for the circular economy. Brussels: COM (2015) 614 final; 2015

20. European Environment Agency (EEA). Circular by design. Copenhagen: Products in the Circular Economy; 2017.

21. Federal Ministry of Education and Research. Green economy research agenda. Bonn: German Government; 2015.

22. Fullerton D. Six distributional effects of environmental policy. CESifo working paper 3299. Germany: Ifo Institute - Leibniz Institute for Economic Research at the University of Munich; 2010.

23. Future Earth. Strategic research agenda 2014. Priorities for a global sustainability research strategy. Paris: International Council for Science (ICSU); 2014

24. Geels FW. From sectoral systems of innovation to socio-technical systems: insights about dynamics and change from sociology and institutional theory. Res Policy. 2004:33:897-920.

25. Gibbs D. Sustainability entrepreneurs, Ecopreneurs and the development of a sustainable economy. Greener Manag Int. 2009:51:63-78.

26. Gibbs D, O'Neill K. Future green economies and regional development: a research agenda. Reg Stud. 2017;51(1):161-73.

27. Greening LA, Greene DL, Difiglio C. Energy efficiency and consumption the rebound effect - a survey. Energy Policy. 2000;28(6-7):389-401.

28. Harford T. Fifty things that made the modern economy. London: Little, Brown; 2017.

29. Hellsmark H, Frishammar J, Söderholm P, Ylinenpää $H$. The role of pilot and demonstration plants in technology development and innovation policy. Res Policy. 2016:45:1743-61.

30. Heshmati A. A review of the circular economy and its implementation. Int J Green Econ. 2017:11(3/4):251-88.

31. Heshmati A. An empirical survey of the ramifications of a green economy Int J Green Econ. 2018;12(1):53-85.

32. Huenteler J, Schmidt T, Ossenbrink J, Hoffman V. Technology life-cycles in the energy sector - technological characteristics and the role of deployment for innovation. Technol Forecast Soc Chang. 2016;104:102-21.

33. International Energy Agency (IEA). Ensuring green growth in a time of economic crisis: the role of energy technology. Siracusa: IEA; 2009

34. Jacobsson S, Bergek A. Innovation system analyses and sustainability transitions: contributions and suggestions for research. Environ Innov Soc Transit. 2011;1:41-57.

35. Kirby $\mathrm{P}, \mathrm{O}$ 'Mahony $\mathrm{T}$. The political economy of the low-carbon transition Pathways beyond techno-optimism. London: Palgrave McMillan; 2018.

36. Kivimaa P, Kern F. Creative destruction or mere niche support? Innovation policy mixes for sustainability transitions. Res Policy. 2016;45(1):205-17.

37. Larson AL. Sustainable innovation through an entrepreneurship lens. Bus Strateg Environ. 2000;9:304-17

38. Lehmann P, Söderholm P. Can technology-specific deployment policies be cost-effective? The case of renewable energy support schemes. Environ Resour Econ. 2018;71:475-505.

39. Levin RC, Klevoriek AK, Nelson RR, Winter SG. Appropriating the returns from industrial research and development. Brook Pap Econ Act. 1987;3:783-820. 
40. Markard J, Raven R, Truffer B. Sustainability transitions: an emerging field of research and its prospects. Res Policy. 2012;41:955-67.

41. Megwai G, Njie NI, Richards T. Exploring green economy strategies and policies in developing countries. Int J Green Econ. 2016;10(3/4):338-57.

42. Moberg Å, Finnveden G, Johansson J, Lind P. Life cycle assessment of energy from solid waste - part 2: landfilling compared to other treatment methods. J Clean Prod. 2005;13(3):231-40.

43. Neuhoff K. Large-scale deployment of renewables for electricity generation. Oxf Rev Econ Policy. 2005;21(1):88-110.

44. Newell P. Globalization and the environment: capitalism, ecology and power. Cambridge: Cambridge University Press; 2012

45. Newell P, Paterson M. Climate capitalism: global warming and the transformation of the global economy. Cambridge: Cambridge University Press; 2010

46. Nicolli F, Johnstone N, Söderholm P. Resolving failures in recycling markets: the role of technological innovation. Environ Econ Policy Stud. 2012;14(3):261-88.

47. Organization of Economic Cooperation and Development (OECD) Sustainable manufacturing and eco-innovation. Framework, practices and measurement. Paris: OECD; 2009.

48. Organisation for Economic Cooperation and Development (OECD). Interim report of the green growth strategy: implementing our commitment for a sustainable future. Paris: OECD; 2010.

49. Popp D, Newell R. Where does energy R\&D come from? Examining crowding out from energy R\&D? Energy Econ. 2012;34(4):980-91.

50. Rodrik D. Green industrial policy. Oxford Rev Econ Policy. 2014;30(3):469-91.

51. Rogge KS, Reichardt K. Policy mixes for sustainability transitions: an extended concept and framework for analysis. Res Policy. 2016;45(8):1620-35.

52. Söderholm P, Hellsmark H, Frishammar J, Hansson J, Mossberg J, Sandström A. Technological development for sustainability: the role of network management in the innovation policy mix. Technol Forecast Soc Chang. 2019;138:309-23.

53. Stein JC. Efficient capital markets, inefficient firms: a model of myopic corporate behavior. Q J Econ. 1989;104:655-69.

54. United Nations Environment Programme (UNEP). Towards a green economy: pathways to sustainable development and poverty eradication. Nairobi: United Nations; 2011

55. United Nations Environment Programme (UNEP). A guidance manual for green economy policy assessment. New York: United Nations; 2014.

56. United Nations Framework Convention on Climate Change (UNFCCC). 2016 biennial assess-ment and overview of climate finance flows report. Bonn: United Nations; 2016.

57. Unruh GC. Understanding carbon lock-in. Energy Policy. 2000;28(12):817-30.

58. Van Ewijk S, Stegemann JA. Limitations of the waste hierarchy for achieving absolute reductions in material throughput. J Clean Prod. 2016;132:122-8.

59. Walls M, Palmer K. Upstream pollution, downstream waste disposal, and the design of comprehensive environmental policies. J Environ Econ Manag. 2001:41:94-108.

60. Williamson O. Credible commitments: using hostages to support exchange. Am Econ Rev. 1983;73:519-40.

\section{Publisher's Note}

Springer Nature remains neutral with regard to jurisdictional claims in published maps and institutional affiliations.

\section{Ready to submit your research? Choose BMC and benefit from:}

- fast, convenient online submission

- thorough peer review by experienced researchers in your field

- rapid publication on acceptance

- support for research data, including large and complex data types

- gold Open Access which fosters wider collaboration and increased citations

- maximum visibility for your research: over $100 \mathrm{M}$ website views per year

At BMC, research is always in progress.

Learn more biomedcentral.com/submissions 